This is the editor version of the following published document:

Llorente, A., Serrano, B., Baselga; J., Gedler, G.

\& Ozisik, R. (2016). Nanoindentation and wear

behavior of thermally stable biocompatible

polysulfone-alumina nanocomposites. RSC

Advances, 6 (102), pp. 100239- 100247.

DOI: $10.1039 / \mathrm{c} 6 \mathrm{ra} 20838 \mathrm{j}$

(C) The Royal Society of Chemistry, 2016

This document is the final edited and published Author's version that was accepted for publication RSC Advances, copyright (C) The Royal Society of Chemistry, 2016. To access the final edited and published work see http:// pubs.rsc.org/-/content/articlelanding/2016/ra/c6ra20838j

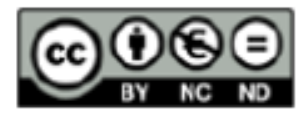

This work is licensed under a Creative Commons Attribution-NonCommercialNoDerivatives 4.0 International License. 


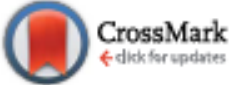

Cite this: RSC Adv., 2016, 6, 100239
Received 18th August 2016 Accepted 11th October 2016

DOI: $10.1039 / \mathrm{c} 6 \mathrm{ra} 20838 \mathrm{j}$

wuw.rsc.org/advances

\section{Nanoindentation and wear behavior of thermally stable biocompatible polysulfone-alumina nanocomposites $\dagger$}

\begin{abstract}
Amaia Llorente, ${ }^{\star a}$ Berna Serrano, ${ }^{a}$ Juan Baselga, ${ }^{a}$ Gabriel Gedler ${ }^{b}$ and Rahmi Ozisik ${ }^{b}$
Besides improving mechanical performance, wear resistance is the first prerequisite for a dental material to be accepted by both dentists and patients, and therefore good wear behavior may contribute to the longevity and durable aesthetics of a dental material such as brackets or implants. In this work we have investigated the wear and mechanical behavior, along with the thermal stability, of polysulfone/modified alumina. $\gamma$-Alumina nanoparticles have been modified with polysulfone (PSU) chains of two different molecular weights. The modification leads to an enhanced homogeneous dispersion, as was confirmed using TEM-image analysis, and enhanced mechanical and wear behavior when compared with a PSU/ alumina nanocomposite. Nanoindentation measurements confirmed that the elastic modulus values were enhanced when modified nanoparticles were used to prepare nanocomposites. Abrasive wear analysis revealed that the wear volume loss was decreased when the nanoparticles were modified. The PSU chains grafted to alumina promoted enhanced particle dispersion, which at the same time induced protection in the polysulfone matrix against wearing off. The results showed a clear tendency for increased strength and wear resistance, without sacrificing transparency. Regarding the thermal stability of the materials prepared, the results showed similar thermal stabilities for both neat PSU and modified particle nanocomposites up to a certain temperature (i.e., $\sim 550^{\circ} \mathrm{C}$ ), and after this temperature these nanocomposites displayed a higher thermal stability than neat PSU.
\end{abstract}

\section{Introduction}

The increasing demand for aesthetics during orthodontic treatment has promoted the development of ceramic and plastic brackets, aimed at replacing metal brackets. ${ }^{1}$ Nowadays a wide array of raw materials are used to fabricate aesthetic brackets, including ceramic, sapphire or single crystal alumina, and polymers, with polycarbonate being the most widely used polymer. The ceramic materials used in manufacturing these brackets provide excellent color stability, transparency and strain resistance, with durability very similar to metal brackets, however they are associated with several problems, such as fracture during torsional movement, ${ }^{2,3}$ excessive abrasion of enamel on opposing teeth ${ }^{4,5}$ and higher frictional resistance compared with metal brackets. ${ }^{6}$

On the other hand, plastic brackets have been shown to be a viable altemative, especially economically, despite their

"Department of Materinls Science and Engineering \& Chemical Engineering Polytechnic School, Carlos III University of Madrid, Avenida Universidad 30, 28911 Leganes, Madrid, Spain E-mail: albrent @ing uc3m.es; Tel: +34-91-6249469 "Department of Materials Sdience and Engineering Rensse her Polytechnic Institute, Troy, $N Y, 12180$, USA

† Electronic supplementary information (ESI) available. See DOI: 10.1039/c6ra20838j reduced hardness and wear resistance. However, unfilled plastic brackets must be replaced often, mainly due to excessive wear. Therefore, in order to provide an effective combination of cost, biocompatibility, transparency, and mechanical and wear resistance, which will allow them to compete with ceramic brackets, ${ }^{7}$ further research is necessary to improve the materials used in plastic brackets.

In this work we have selected polysulfone (PSU) as a raw material, because it is a high-performance polymer, with excellent thermal and mechanical properties, ${ }^{\mathrm{s}, \mathrm{o}}$ used in fields of application as diverse as automotives, electrical engineering, households, mechanical engineering, water filtration, etc., with high potential for bioengineering applications. ${ }^{10}$ PSU seems to be an alternative candidate for a raw material, as it fulfills the requirements of biocompatibility, transparency, high chemical resistance, mechanical strength and relatively high toughness. Nevertheless, despite these advantages, it seems that neat PSU exhibits relatively poor wear resistance under certain conditions. One of the strategies used to counteract the poor wear resistance of PSU is the addition of different types of nanofillers, ${ }^{11}$ aimed at expanding the applications of this polymer.

The wear resistance is a key prerequisite for a material proposed for use in dental applications, and needs to be accepted by both dentists and patients, because it may contribute to the longevity and durable aesthetics of a dental 
material. Many researchers have reported that the wear resistance of polymers has been improved through the addition of nanoparticles such as $\mathrm{Al}_{2} \mathrm{O}_{3}, \mathrm{SiC}, \mathrm{TiO}_{2}$, and $\mathrm{ZnO}$, among others. ${ }^{12-15}$ But other studies have demonstrated opposite results, i.e., the deterioration of wear resistance. ${ }^{16}$ Therefore it is not valid to assume that nanofillers always improve wear behavior, because although the reinforcing nanofillers increase the strength of the polymer matrix, they also could increase the abrasiveness of the interacting surfaces in relative motion. ${ }^{17}$

On the other hand, it is well known that to improve polymer nanocomposite properties, the optimal dispersion of nanoparticles within polymer matrices is critical. However, achieving effective dispersions of hard inorganic nanoparticles is intrinsically difficult due to particle-matrix strong enthalpic incompatibility and the particle tendency to form aggregates. ${ }^{13,10}$ In addition, under tribological conditions, this can result in extensive material loss due to crumbling of the particle agglomerates and self-scratching, irreversibly damaging the polymer. In order to control the dispersion of nanoparticles in the polymer matrix, nanoparticle surfaces are typically modified with either short molecules or long polymer brushes. ${ }^{20-22}$ The interface between the nanoparticles and the polymer coating plays a key role in the final dispersion of particles and consequently in the final properties of the material. The scope of this manuscript is to graft PSU chains onto $\mathrm{Al}_{2} \mathrm{O}_{3}$ nanoparticles to hinder the aggregation and agglomeration of the particles when they are included in a PSU matrix. The surface modification process starts with the preparation of vinyl functionalized alumina nanoparticles; subsequently, azide terminated PSU chains (PSU-N ${ }_{3}$ ) are attached covalently. Furthermore, the focus of this work is to demonstrate the superior properties of a nanocomposite of PSU with PSU grafted-nanoparticles, through the characterization of the mechanical and wear behavior. Thus, with better dispersion, PSU-alumina nanoparticles in a stable dispersed state result in an increase in the elastic modulus and wear resistance of the nanocomposite without losing transparency.

\section{Experimental}

\section{Materials}

$\gamma$-Alumina nanoparticles were purchased from Sigma-Aldrich with a density of $3.29 \mathrm{~g} \mathrm{~cm}^{-3}$, measured using a helium pycnometer, and a specific surface area of $180 \mathrm{~m}^{2} \mathrm{~g}^{-1}$, determined using nitrogen adsorption and desorption isotherms and analyzed using the BET method (Micromeritics Gemini VII). Commercial PSU (Sigma-Aldrich), with $M_{\mathrm{n}}=16000 \mathrm{~g} \mathrm{~mol}^{-1}$ and $M_{\mathrm{w}}=35000 \mathrm{~g} \mathrm{~mol}^{-1}$, was used as the polymer matrix. Two different PSUs, with low and high molecular weight, were used as grafting polymers. The low molecular weight one was synthesized in this work (short chains) and the longer one was the same as that used in the polymer matrix (long chains).

\section{Synthesis of modified nanoparticles}

Two types of PSU-grafted nanoparticles were prepared through the "grafting to" approach, using PSU with low molecular weight (PSU 2.4k) and commercial PSU with high molecular weight (PSU 16k).

Polysulfone of low molecular weight was synthesized according to the reaction reported by Dizman. ${ }^{23}$ The molecular weight was determined using sizeexclusion chromatography (SEC), performed on a Shimadzu LC-20AD pump with a UVvisible detector (Waters 2487 dual $\mathrm{k}$ absorbance detector) and IR detector (Waters 2410 differential refractometer). Tetrahydrofurane (THF, $\geq 99 \%$ ) was used as eluent, with a flow rate of $1 \mathrm{ml} \mathrm{min}^{-1}$ at $35^{\circ} \mathrm{C}$. The molecular weight was calculated with calibration relative to the following polystyrene standards: $M_{\mathrm{w}}=$ $5633 \mathrm{~g} \mathrm{~mol}^{-1}$ and $M_{\mathrm{n}}=2295 \mathrm{~g} \mathrm{~mol}^{-1}$, with PDI $=2.4 . \mathrm{H}-\mathrm{NMR}$ was also used to calculate the following: $M_{\mathrm{n}}=2537 \mathrm{~g} \mathrm{~mol}^{-1}$ (300 MHz, DMSO), $\delta=6.8$ and 7.1 (Ar-H end groups), and $\delta=$ $6.9,7.2$ and $7.9(\mathrm{Ar}-\mathrm{H})$.

The incorporation of azide end groups in PSU ( $\left.\mathrm{N}_{3}-\mathrm{PSU}\right)$ was done in two steps: first, the introduction of the chlorine end group using 2-chloroethyl isocyanate, following the method reported in the literature, ${ }^{24}$ and subsequently, the transformation of the chlorine end group to an azide end group using sodium azide, through nucleophilic substitution.

For the functionalization of the $\gamma$-alumina nanoparticles with polysulfone, either short chain or long chain, in the first step the nanoparticles were pre-functionalized with vinyltrimethoxysilane (VTMS) (supplied by Aldrich-Sigma) in order to incorporate double bonds on the surface. The surface functionalization of the $\gamma$-alumina nanoparticles with VTMS was performed following the protocol established by Gupta and Tsubokawa for silanes. ${ }^{25,26}$

At this point we must clarify that double bonds like vinyl groups are tolerated to a certain extent, given that they are not electronically activated, since there is no substituent on the $\mathrm{C}=\mathrm{C}$ double bond to accelerate the reaction. ${ }^{27,28}$ Nevertheless, it has been reported that azide groups form a triazoline compound, reacting with a vinyl bond at elevated temperatures (higher than $80^{\circ} \mathrm{C}$ ). ${ }^{20}$ Hence, it is possible to obtain adequate yields of the triazoline compound if the temperature and time of reaction are optimized, i.e., at $180^{\circ} \mathrm{C}$ and for $72 \mathrm{~h}$. Fig. 1 shows a schematic representation of how the azide modifiedPSU was grafted onto the alumina nanoparticles using an azide/alkene reaction.

After the grafting process, the obtained product contains the triazoline group. ${ }^{27}$ However, in most cases triazolines are unstable and decompose to form an aziridine or mostly an imine structure.

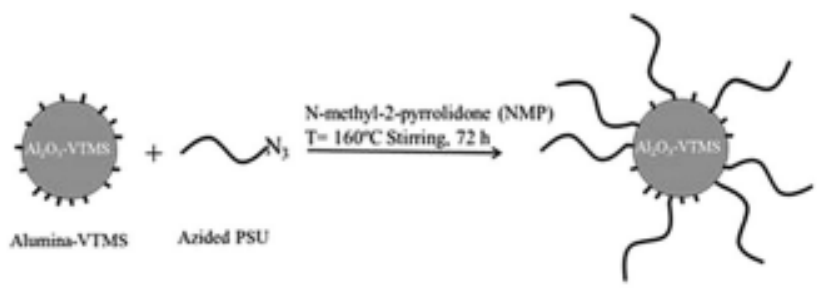

Fig. 1 Schematic representation of a PSU-grafted $\gamma$-alumina nanoparticle. 
This fact can be confimed from the FTIR spectrum (shown in Fig. S1 ${ }^{\dagger}$ ), through the presence of a new peak at about 1652 $\mathrm{cm}^{-1}$, assigned to imine $-\mathrm{C}=\mathrm{N}$ stretching ${ }^{\text {to }}$ (see details in the ESI+).

\section{Fabrication of the nanocomposites}

These PSU grafted nanoparticles (denoted as PSU 2.4k_ $\mathrm{Al}_{2} \mathrm{O}_{3}$ and PSU 16k_ $\mathrm{Al}_{2} \mathrm{O}_{3}$ ) were incorporated into a matrix polymer (PSU 16k, $M_{\mathrm{n}}=16000 \mathrm{~g} \mathrm{~mol}^{-1}$ ) through melt compounding at 2,5 and $10 \mathrm{wt} \%$ loadings and a subsequent injection process, in a similar way to our previous work. ${ }^{10}$

The following abbreviations are used in this work: PSU/ $X \mathrm{Al}_{2} \mathrm{O}_{3}$, where $X$ represents the nanoparticle content (i.e., 2, 5 or $10 \mathrm{wt} \% \gamma$-alumina), and PSU/PSU $2.4 \mathrm{k} \mathrm{XAl}_{2} \mathrm{O}_{3}$ and PSU/PSU $16 \mathrm{k} \_X \mathrm{Al}_{2} \mathrm{O}_{3}$ for the grafted alumina systems with nanocomposites containing PSU 2.4k grafted (short chain) and PSU 16k grafted (long chain) $\gamma$-alumina nano-reinforcements, at the same level (with $X=2,5$ or $10 \mathrm{wt} \%$ ). It is important to point out that the addition of these nanoparticles did not compromise the transparency of the materials (Fig. S2 + ).

\section{Methods and measurements}

Fourier transform infrared spectroscopy (FTIR) of the modified alumina was performed using a Perkin Elmer Spectrum GX2000 spectrometer with a resolution of $1 \mathrm{~cm}^{-1}$ over a scale range of $4000-400 \mathrm{~cm}^{-1}$. This technique was used to confirm the presence of imine groups after the grafting process.

We report a comprehensive analysis of the prepared materials using elemental analysis and X-ray photoelectron spectroscopy (XPS) with the aim of confirming successful functionalization with VTMS and PSU chains at the alumina surface.

XPS measurements were performed using a PHI 5000 Versa Probe, using a $50 \mathrm{~W}$ Al $\mathrm{K} \alpha \mathrm{X}$-ray probe beam (1486.6 eV).

In order to support the XPS results, the FT-Raman technique was implemented. FT-Raman measurements were obtained using a Bruker (D) FRA-106/S component attached to an EQUINOX 55 spectrometer. Spectra shown in this work are from an average of 100 scans at $4 \mathrm{~cm}^{-1}$ resolution, while the intensity of Nd:YAG on the samples was $250 \mathrm{~mW}$.

The dispersion of the different particles was observed using transmission electron microscopy (TEM) imaging, where samples of modified and bare alumina powders were previously dispersed in acetone solvent and sonicated for $30 \mathrm{~min}$. Subsequently, the samples were placed onto carbon TEM grids (Ted Pella 400 mesh). The TEM images were acquired using a JEOL JEM-2011 LaB6 at $200 \mathrm{kV}$ with an AMT-XR280 side mount camera.

Thermogravimetric analysis (TGA) was used to estimate the content of PSU chains after the grafting process, and the thermal stability of the nanocomposites. The experiments were carried out using a TGA Perkin Elmer STA 6000. Sample masses ranging from 15 to $20 \mathrm{mg}$ were heated from 50 to $900^{\circ} \mathrm{C}$ at a rate of $10^{\circ} \mathrm{C} \mathrm{min}{ }^{-1}$ under a dry air atmosphere.

The nanoindentation study was carried out using a Hysitron TI900 Tribodenter Nanoindenter employing a Berkovich indenter
(100 $\mathrm{nm}$ radius of curvature, and angle of $142.3^{\circ}$ ). The instrument was calibrated through performing a series of indentations on standard materials (alumina and quartz). The optimal conditions found from preliminary attempts for this test were as follows: a load of $8000 \mu \mathrm{N}$, with loading and unloading times both of $10 \mathrm{~s}$. An average of 21 indentations was considered for each sample.

The tribological properties of the nanocomposites, friction coefficients and wearing rates, were measured against counterfaces and tested using a Tribometer Microtest MT/10/SCM. The testing parameters used were as follows: a normal force of $5 \mathrm{~N}$, and a speed of $75 \mathrm{rpm}$, with a stroke of $50 \mathrm{~m}$. The tests were performed in air at room temperature $\left(20 \pm 2{ }^{\circ} \mathrm{C}\right)$. After each test, the specimens were removed from the sample holder and weighed, and a mass loss was recorded.

Field emission scanning electron microscopy (FEI Teneo LV SEM) was used to investigate the modified nanoparticle dispersion within the matrix, using a voltage and working distance of $1 \mathrm{kV}$ and $3.5 \mathrm{~mm}$ respectively.

The footprints formed after the wear test were analyzed using a scanning electron microscope (SEM, Philips XL30), using a voltage of $20 \mathrm{kV}$ and a working distance of $10.5 \mathrm{~mm}$.

\section{Results and discussion}

\section{Surface modification of the nanoparticles}

Fig. 2 displays the XPS spectra of the bare $\mathrm{Al}_{2} \mathrm{O}_{3}$, VTMS_Al $\mathrm{Al}_{2} \mathrm{O}_{3}$ and PSU 2.4k_ $\mathrm{Al}_{2} \mathrm{O}_{3}$ samples. The elemental analysis employed displayed the high-resolution $\mathrm{O}$ 1s spectra (Fig. 2a) of alumina, which revealed two peaks at 530.6 and $532.2 \mathrm{eV}$, which were attributed to oxygen from the $\mathrm{O}-\mathrm{H}$ component of aluminum oxohydrides and to oxygen from the Al-O component of alumina, respectively. The appearance of a new peak at $531.1 \mathrm{eV}$ (corresponding to oxygen in Al-O-Si), after surface modification, indicates chemical bonding between VTMS and aluminum oxide (Fig. 2b). These values agree with what has been previously reported by Gupta ${ }^{25}$ for developing allyl-functionalized alumina nanoparticles, carried out with allyltrimethoxysilane (ATMS). Nevertheless, a small signal above $533 \mathrm{eV}$, attributed to O-C, appears due to the presence of methoxy groups that did not react with alumina $\mathrm{OH}$ groups.

After the grafting process (Fig. 2c), the $\mathrm{C}$ 1s peak can be fitted to $\mathrm{C}=\mathrm{C}, \mathrm{C}-\mathrm{S}$ and $\mathrm{C}-\mathrm{O}$ due to the polysulfone backbone (the attached spectrum is only for short chain grafting). ${ }^{31}$ The peaks at $285.3 \mathrm{eV}$ and $286.2 \mathrm{eV}$ are assigned to $\mathrm{C}-\mathrm{S}$ and $\mathrm{C}-\mathrm{O} / \mathrm{C}-\mathrm{N}$, respectively. ${ }^{12-34}$ The signals detected are associated with the presence of PSU, confirming the successful grafting of PSU molecules onto the nanoparticles.

Additionally, a comparison of the Raman spectra for the bare, VTMS-modified and PSU-modified nanoparticles (shown in Fig. S34), also allowed us to confirm the presence of PSU on the nanoparticle surface.

The estimation of the content of PSU chains after the grafting process was correlated to the graft density $(\sigma)$ using the following equation: $\sigma=\Delta m N_{\mathrm{A}} /(100-\Delta m) M S_{\mathrm{p}} \times 10^{18}$, where $\Delta m$ and $M$ correspond to the weight loss and molecular weight of the grafted chains of PSU, respectively, $S_{\mathrm{p}}$ is the specific area of the nanoparticles and $N_{\mathrm{A}}$ is Avogadro's number. ${ }^{.5}$ 

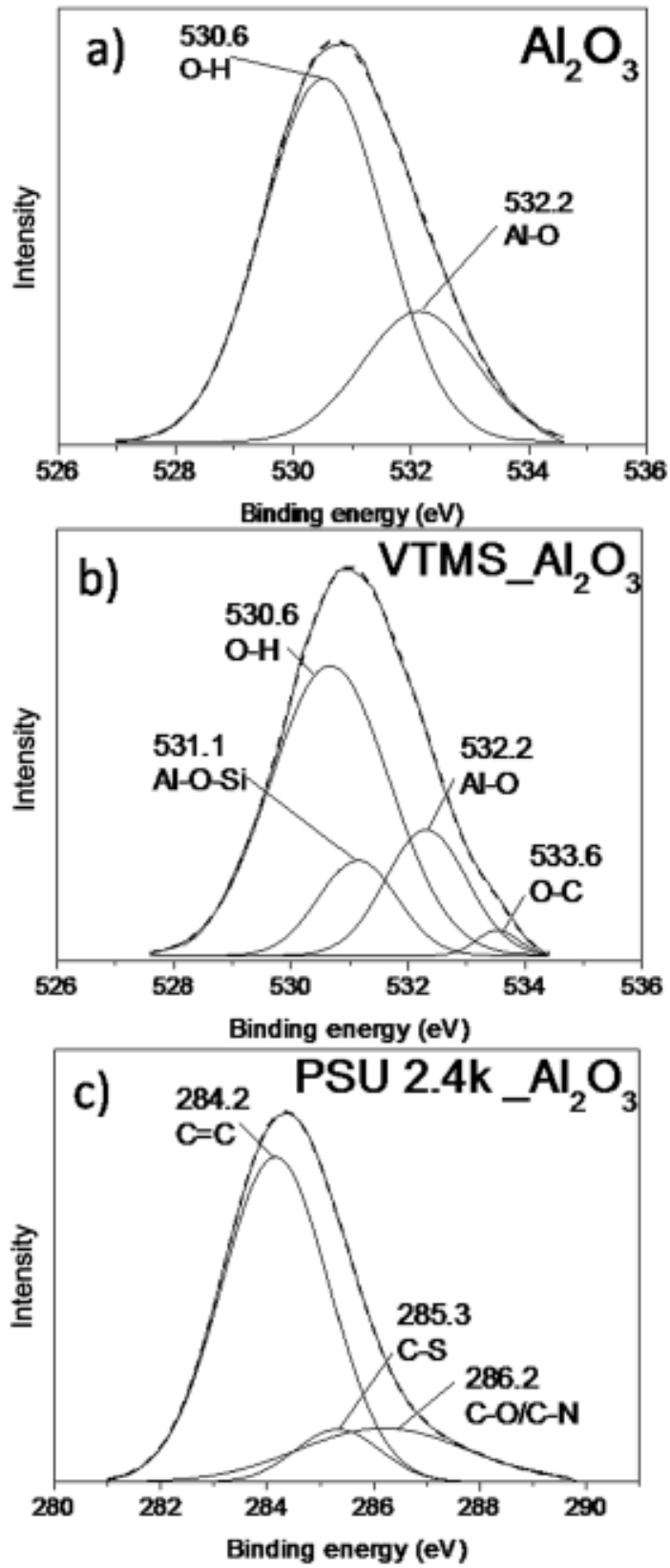

Fig. 2 XPS spectra of $\mathrm{O}$ 1s for (a) $\mathrm{Al}_{2} \mathrm{O}_{3}$ and (b) VTMS_Al $\mathrm{Al}_{2} \mathrm{O}_{3}$; and (c) the spectra of carbon ( $C 1 \mathrm{~s}$ ) after the PSU $2.4 \mathrm{k}$ grafting process (PSU 2.4k_ $\mathrm{Al}_{2} \mathrm{O}_{3}$ ).

The graft density for the short PSU chains was 0.069 chains per $\mathrm{nm}^{2}$, while for the long PSU chains it was 0.015 chains per $\mathrm{nm}^{2}$, indicating that the short chains (PSU 2.4k) allowed a higher amount of PSU covalent attachment onto the particle surface when compared to the long molecules (see the ESI for a detailed explanation and Fig. $\mathrm{S} 3 \dagger$ for a schematic representation).

The effect of the grafting process on the dispersion state was studied using transmission electron microscopy. Fig. 3a shows the dispersion of the bare alumina particles that tended to aggregate.
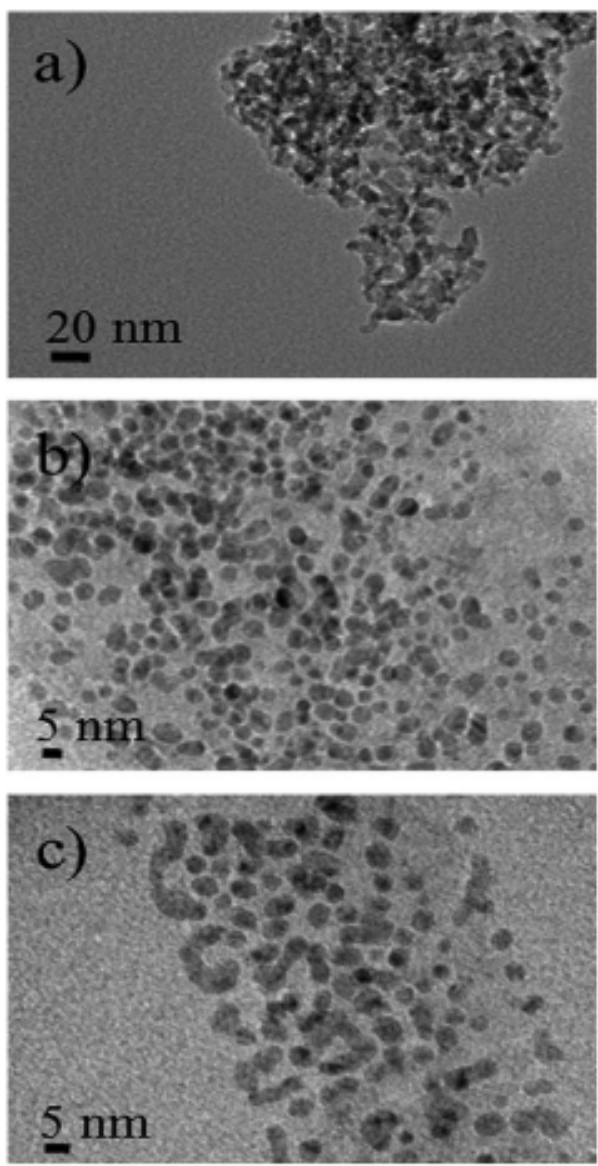

Fig. 3 TEM images of samples of (a) bare $\mathrm{Al}_{2} \mathrm{O}_{3}$, (b) PSU $2.4 \mathrm{k} \_\mathrm{Al}_{2} \mathrm{O}_{3}$, and (c) PSU $16 \mathrm{k} \_\mathrm{Al}_{2} \mathrm{O}_{3}$.

The TEM micrographs (Fig. $3 \mathrm{~b}$ and c) suggest that the nanoparticle surface functionalization with PSU chains is capable of avoiding particle aggregation, keeping the particles away from each other due to the presence of PSU molecules. This effect made it possible to observe the real morphology of the nanoparticles. From these TEM images, it was possible to estimate the size of the alumina particles $(5.1 \pm 1.0 \mathrm{~nm})$. In the case of PSU 16k_ $\mathrm{Al}_{2} \mathrm{O}_{3}$ (Fig. 3c) it is suggested that the particleparticle distance is in general a bit larger than in the two other cases.

Regarding the dispersion of particles within the nanocomposites, FESEM images of the fracture surfaces are shown for each of the nanocomposites prepared with unmodified (Fig. 4a) and PSU-modified particles (Fig. 4b and c). Fig. 4a shows the presence of agglomerates with an average size of 25.3 $\mu \mathrm{m}$. This result was expected because of the presence of big aggregates of bare alumina before fabrication of the nanocomposite.

For the PSU/PSU 2.4k_5 $\mathrm{Al}_{2} \mathrm{O}_{3}$ and PSU/PSU $16 \mathrm{k}_{-} 5 \mathrm{Al}_{2} \mathrm{O}_{3}$ nanocomposites, the FESEM images show holes without nanoparticles, indicating that particles have fallen out of the surface, because debonding has occurred between the particles and the polysulfone matrix during fracture. This normally occurs with micro-sized particles or, as happens here, with 

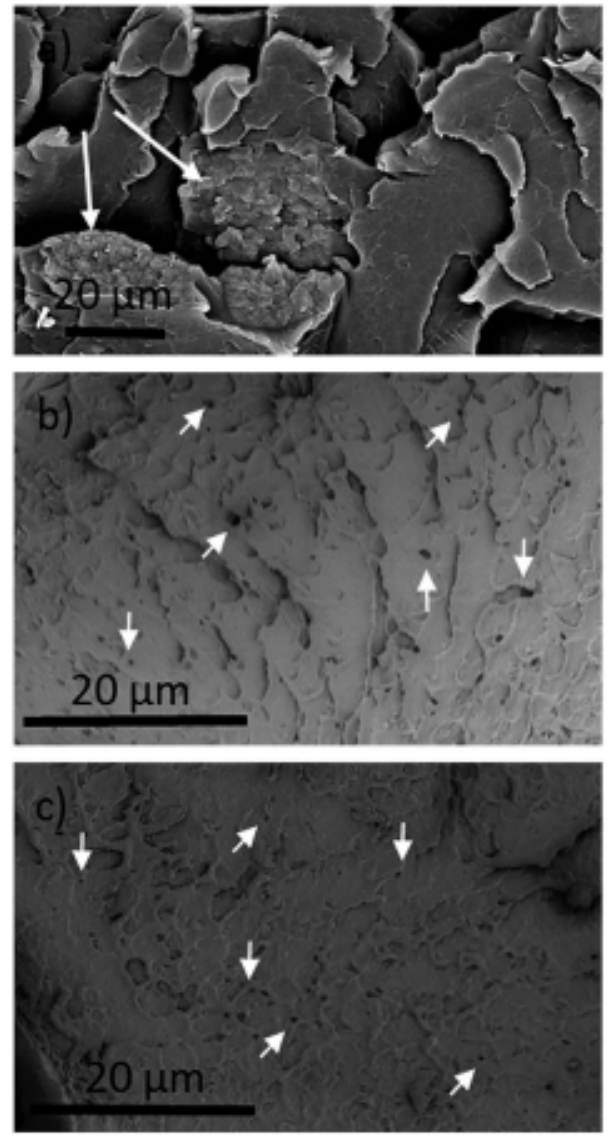

Fig. 4 FESEM images of the nanocomposites: (a) $\mathrm{PSU} / 2 \mathrm{Al}_{2} \mathrm{O}_{3}$ composite, (b) PSU/PSU 2.4k $\mathrm{K}_{5} \mathrm{Al}_{2} \mathrm{O}_{3}$ composite and (c) PSU/PSU $16 \mathrm{k}_{1} 5 \mathrm{Al}_{2} \mathrm{O}_{3}$. The white arrows indicate holes where nanoparticles have fallen out of the surface during fracture.

nanoparticle aggregates. The average hole diameter is about $970 \mathrm{~nm}$ for PSU/PSU 2.4k_5 $\mathrm{Al}_{2} \mathrm{O}_{3}$ and $610 \mathrm{~nm}$ for PSU/PSU 16k_5 $\mathrm{Al}_{2} \mathrm{O}_{3}$. This means that the size of the aggregates is smaller when the nanoparticles are covered with PSU 16k (large chains), indicating better dispersion. In any case, these sizes are much smaller compared with the agglomerates formed with bare particles (Fig. 4a).

This behavior agrees with the previous statements made regarding the particle dispersion analysis using TEM. It can be suggested that a fairly good distribution and dispersion of the modified alumina nanoparticles into the PSU matrix took place after processing the nanocomposites (using extrusion and injection molding), since the presence of aggregates was not detected when the nanoparticles were modified.

\section{Thermal stability of the nanocomposites}

The thermal decomposition in air of PSU and the nanocomposites prepared occurred in three stages, as can be seen in Fig. 5a.

The major mechanism for PSU is one-stage pyrolysis, involving main-chain random scission and carbonization. ${ }^{36}$ It is well known that the two weakest bonds in PSU are the carbonsulfur bond between the aromatic rings and the sulfone group,
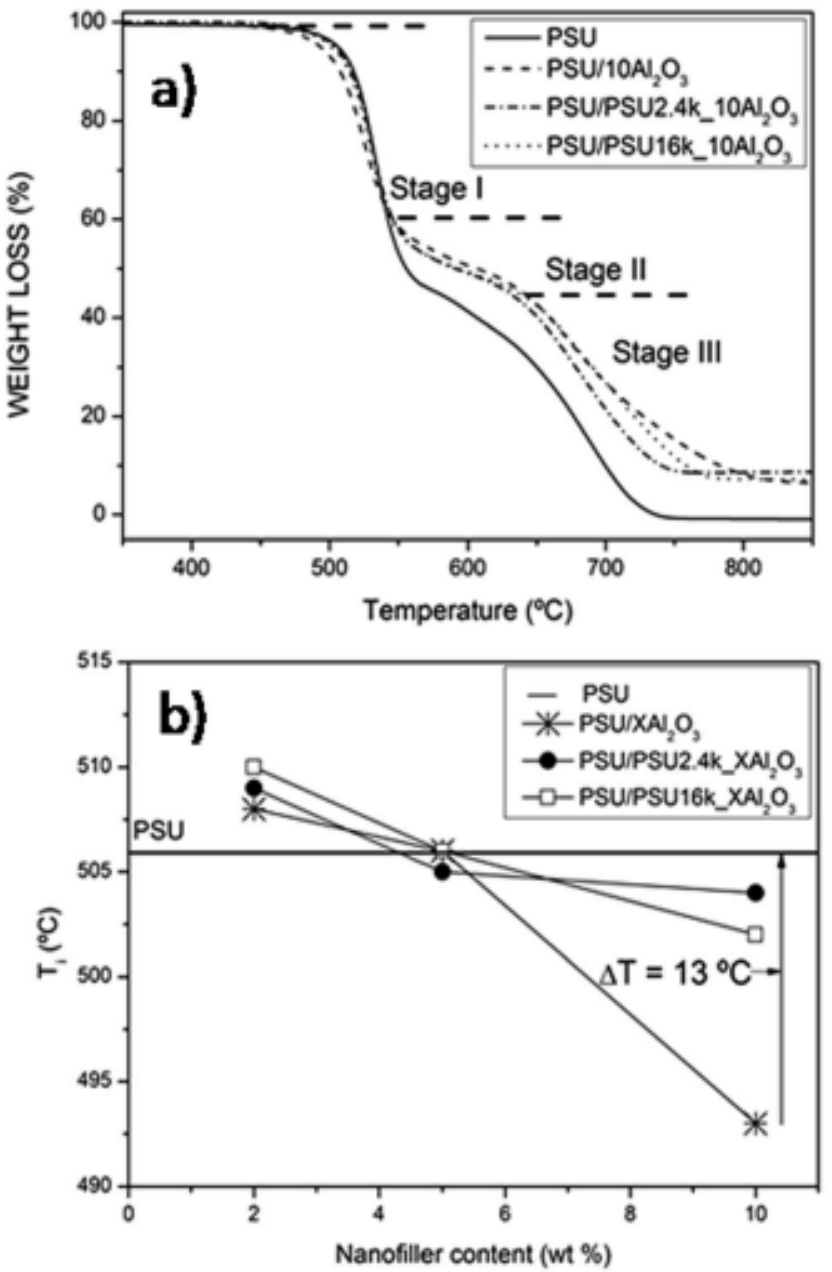

Fig. 5 (a) TGA weight loss versus temperature for PSU and the nanocomposites at $10 \mathrm{wt} \%$ alumina, and (b) initial decomposition temperature, defined as $5 \%$ weight loss, of the nanocomposites $(T)$ versus nanofiller content (wt\%). The horizontal line corresponds to PSU data.

and the carbon-carbon bond between the methyl group and the central carbon of the isopropylidene moiety. ${ }^{37}$

The second stage of degradation presented a lesser mass loss slope than the first main stage of degradation. This stage was attributed to the decomposition of the remaining polymer, which was kept protected from burning due to the char layer formed during stage $I$, as well as the degradation of part of that previous char layer, as has been reported for other polymer systems. ${ }^{ \pm 0}$ The third stage can be attributed to char oxidation produced in previous stages that allows trapped gases to escape. $^{39}$

It has been reported that the thermal stability of polysulfone can be modified with the addition of ceramic nanoreinforcements. It has been found that the presence of nanoparticles does not remarkably enhance the thermal stability of polysulfone, with it showing just a slight improvement upon the addition of nanofiller. . $^{37,40,41}$

In this work, the addition of the bare alumina nanoparticles at a higher loading had a detrimental effect on the 
early thermal stability of the polymer matrix (see Fig. 5a). Fig. 5b shows the initial decomposition temperature, defined as $5 \%$ weight loss of the nanocomposites $\left(T_{\mathrm{i}}\right)$, and Table $\mathrm{S} 1 \uparrow$ shows the temperature at the maximum rate of thermal degradation for neat PSU and the different composites prepared, $T_{\max }$. As is known, the bare alumina surface has a large number of $\mathrm{OH}$ groups."2 These groups can initiate a process of catalytic degradation in the polysulfone matrix through the formation of highly reactive ${ }^{\circ} \mathrm{OH}$ free radicals at high temperature, which have the ability to react with organic compounds. Therefore, the initial decomposition temperature at $5 \%$ weight loss is observed at a lower temperature $\left(13^{\circ} \mathrm{C}\right)$ when compared to neat PSU.

However, for a low content of nanoparticles (i e., 2 wt \%), the nanocomposites displayed a higher thermal stability with the modified nanoparticles, when compared to the bare nanoparticles. Specifically, the longer polymer chains (i.e., PSU 16k) enhanced the thermal stability of the nanocomposites the most. This could be attributed to better dispersion of the modified nanoparticles, suggesting that better interactions in the modified nanoparticle matrix are taking place.

\section{Nanoindentation test}

Fig. 6 displays the results from the nanoindentation test in terms of the elastic modulus and hardness as a function of material type. The modulus values were calculated using the Oliver-Pharr equation $(\mathrm{O}-\mathrm{P}):^{43}$

$$
1 / E_{\mathrm{r}}=\left(1-\nu^{2}\right) / E+\left(1-\nu_{\mathrm{i}}^{2}\right) / E_{\mathrm{i}}
$$

where $\nu$ and $\nu_{\mathrm{i}}$ are the Poisson ratios of the sample and indenter, respectively ( 0.33 and 0.07 ), while $E$ and $E_{\mathrm{i}}$ are the elastic modulus of the polymer and the diamond tip, respectively. The diamond tip is much stiffer than the polymer $\left(E_{\mathrm{i}}=1140 \mathrm{GPa}\right),{ }^{4}$ $E \& E_{\mathrm{i}}$, and thus the O-P equation is reduced to:

$$
1 / E_{\mathrm{r}} \approx\left(1-\nu^{2}\right) / E
$$

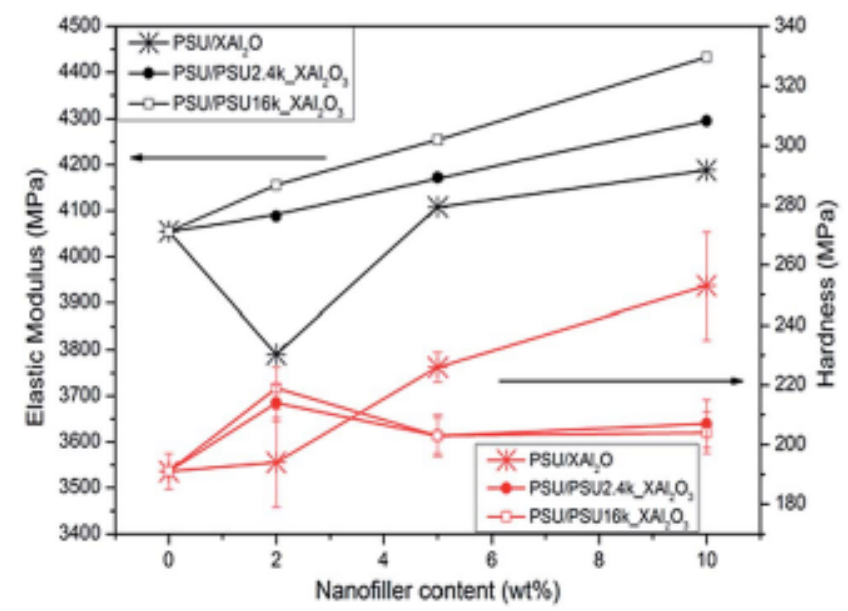

Fig. 6 Values of the elastic modulus and hardness for PSU and the nanocomposites.
It was observed that in most cases the elastic modulus was enhanced through increasing the content of nanoparticles. This was expected due to the high value of the elastic modulus of alumina (360 × $\left.10^{3} \mathrm{MPa}\right){ }^{45}$ However, it was noticed that for the $\mathrm{PSU} / 2 \mathrm{Al}_{2} \mathrm{O}_{3}$ composites, the elastic modulus decreased (up to $6 \%)$.

This was attributed to the presence of unmodified nanoparticles that form big aggregates, which promotes discontinuities, contributing to the formation of stress concentrations during indentation, and resulting in a weaker and more brittle material. For higher concentrations (i.e., 5 wt $\%$ and up), it was observed that the elastic modulus was enhanced when compared to neat PSU; this was attributed to the presence of a larger amount of stiffer nanoparticles, which overruled the negative effects of the aggregates, forming a fair distribution of particles and aggregates of particles, and here enhancing the overall mechanical behavior of these nanocomposites.

For the nanocomposites prepared with modified nanoparticles, an enhancement in the interfacial adhesion was expected, which will contribute to the improvement of particlematrix affinity leading to an overall enhanced mechanical behavior of the nanocomposites.

The better affinity of particle-matrix induced by the PSU molecules grafted to the particles lead to the enhancement of the elastic modulus in the nanocomposites, when compared with the nanocomposite prepared with unmodified particles. This can be explained by the fact that the unmodified-particle nanocomposite would display a lower value of elastic modulus in the surrounding areas of the particles (i.e. matrix), due to the low interaction particle-matrix, when compared to the nanocomposites with modified-particles.

It must be pointed out that the values measured using this technique could be overestimated when compared with modulus values measured using techniques such as the tensile test. ${ }^{10}$ It has been reported that differences in these values have been observed depending on the technique used. For instance, Uskokovic ${ }^{* s}$ compared the values for a poly-L-lactic acid/hydroxyapatite system measured using nanoindentation with values from the literature measured using other techniques, such as compression and bending tests, and observed that the highest values were the ones measured using the indentation technique. He suggested that nanoindentation could derive higher modulus values because of the testing locations, which could be free of imperfections, since they are selected for testing using in situ imaging. The bend test determines the modulus on a bulk level, and most likely it will incorporate flaws in the interior of the specimen. In addition, the two methods induce a different stress state in the sample, which could also lead to differences in the measured modulus. Odegard $^{47}$ and Lucas ${ }^{48}$ reported similar behavior with a high density polyethylene and Teflon, respectively.

Fig. 6 also displays the hardness values (in red), which show an increase in the hardness when increasing the bare-alumina content. This can be attributed to the presence of large aggregates, since it was shown that bare aluminatends to form bigger aggregates and it is reported that the presence of these aggregates can lead to a great increase in the hardness. ${ }^{40}$ 
Nevertheless, the modified nanoparticles, as well as their aggregates dispersed in the polymer matrix, seemed to not offer much mechanical resistance during the indentation process.

\section{Friction and wear properties}

Fig. 7 displays the average friction coefficient for different levels of nanofiller content. It can be observed that a friction coefficient for polysulfone of 0.47 was measured. This value agrees with the value previously reported for PSU. ${ }^{50}$ It is evident that the addition of bare alumina nanoparticles played a key role in the friction coefficient, promoting the increase in this parameter when increasing the content of unmodified particles. This phenomenon can be attributed to the fact that the bare alumina nanoparticles are not able to achieve a good interaction with the matrix; therefore, they form big aggregates (as previously discussed). As a consequence, they act as a highly abrasive material, and they can be considered as an extra vehicle for wearing.

The aggregates remain in between both surfaces, promoting a friction increase. Therefore, it can be considered that the mechanism of abrasion taking place is promoted by the presence of alumina nanoparticles, which act as a third body during the abrasion process. ${ }^{11,51}$

There are numerous studies confirming the increase of the friction coefficient from the addition of alumina nanoparticles to different matrices, such as Teflon, polyphenylene sulfide, PET and polymethylene oxide, ${ }^{12,52-5 s}$ as a consequence of the presence of aggregates promoting an increase in the friction coefficient, and the importance of achieving homogeneous dispersions.

Regarding the nanocomposites with modified nanoparticles, an improvement in this parameter was shown due to the functionalization of the nanoparticles, which resulted in an important decrease in aggregate sizes. It has been reported that a smaller particle size induces a lower coefficient of friction. ${ }^{56,57}$

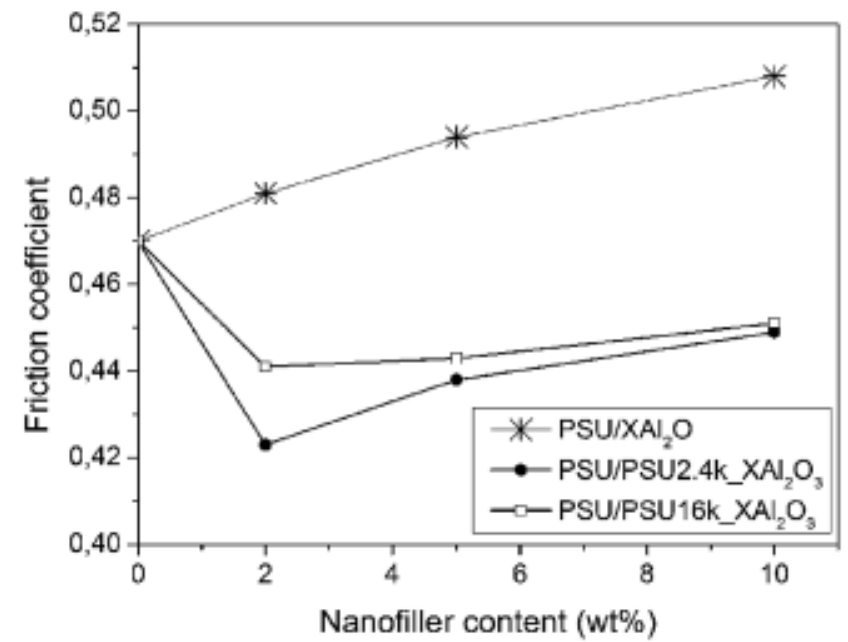

Fig. 7 Friction coefficients of PSU and the nanocomposites as a function of nanoparticle content.
Fig. 8 shows SEM images of the wom surfaces of nanocomposites with $\mathbf{5}$ wt $\%$ alumina content, and PSU for comparison. The presence of large agglomerates for the sample PSU/ $5 \mathrm{Al}_{2} \mathrm{O}_{3}$ can be noted (Fig. 8b). This seemed to promote larger prints on the surface when compared to PSU/PSU $16 \mathrm{k} \_5 \mathrm{Al}_{2} \mathrm{O}_{3}$ (Fig. 8c), where the presence of similar aggregates was not observed. The wear rates (WR) were calculated, estimating the weight loss $(\mathrm{m})$ for each nanocomposite after the test (see the ESI for details $\dagger$ ). Table S2 $\uparrow$ displays the parameters calculated from the weight loss at the end of each experiment. It can be observed that for unmodified alumina nanocomposites (PSU/ $X \mathrm{Al}_{2} \mathrm{O}_{3}$ ), the values of wear volume (WV) and WR were higher than for the PSU/PSU_X $\mathrm{Al}_{2} \mathrm{O}_{3}$ nanocomposites, regardless of the type of PSU used, reaching increments of around $10 \%$.

As has been previously discussed, wear rate is connected with the presence of aggregates,, ss hence, these values will tend to increase when the load of alumina is increased. However, when the nanoparticles were modified, a remarkable decrease (up to $14 \%$ ) in these parameters was observed. It can be noted that this value is higher when compared to the nanocomposites with short PSU chain-modified alumina. The results at this point cannot be completely explained. However, we can suggest that the longer PSU chains promoted higher levels of entanglement with the PSU chains of the matrix. This might promote
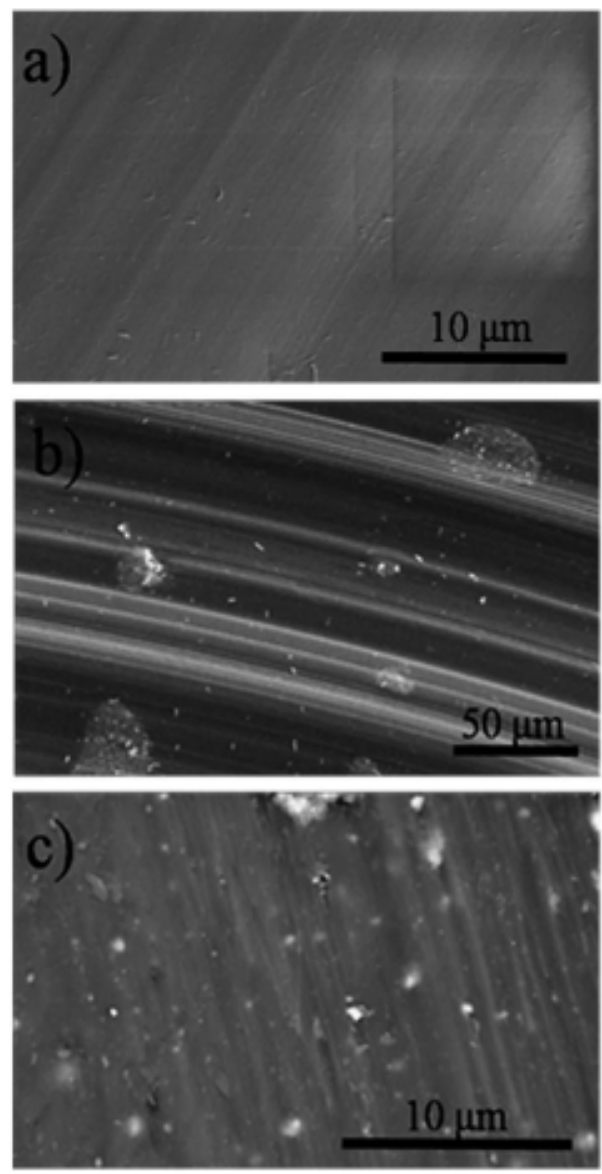

Fig. 8 SEM images of the worn surface of PSU and the nanocomposites: (a) PSU, (b) PSU/5 $\mathrm{Al}_{2} \mathrm{O}_{3}$, and (c) PSU/PSU $16 \mathrm{k}_{-} 5 \mathrm{Al}_{2} \mathrm{O}_{3}$. 
the particles to pull off a larger amount of material, increasing the wearing rate. On the other hand, for the particles modified with shorter PSU chains, the possible lower degree of entanglement would not pull off as much material as in the other case. This behavior has been reported by Dasari et al., ${ }^{11}$ and they confirmed that surface modification of different nanofillers results in an important improvement in the tribological properties because of a decrease in nanofiller size and a better matrix/nanofiller interface.

\section{Conclusions}

Biocompatible polysulfone-alumina nanocomposites were designed and prepared using functionalized alumina nanoparticles and the "grafting to" approach, with two different lengths of polysulfone chains. The presence of PSU molecules grafted to the alumina nanoparticles led to a more homogeneous dispersion of nanoparticles, hindering the formation of large aggregates, as is the case for unmodified alumina. This was visually confirmed using TEM and SEM. In addition, the enhanced particle dispersion also led to improvements in the mechanical frictional wear properties. Nanoindentation analysis showed that the elastic modulus of the nanocomposites increased when using modified nanoparticles, especially those nanoparticles with longer PSU chains, which restricted on a larger scale the formation of large aggregates. The general trend observed was the increase of the elastic modulus with the increase of particle content. The friction and wear analysis indicated that the use of modified nanoparticles in PSU nanocomposites increased the wear resistance of the nanocomposites. This was attributed to the PSU molecules grafted to the nanoparticles, which enhanced the matrix-nanoparticle interactions, reducing the friction coefficient of the nanocomposites when compared to the bare alumina nanocomposites. Additionally, it was shown that the PSU molecules grafted to alumina increased the thermal stability of the nanocomposites at high temperatures (i.e. $>\sim 550^{\circ} \mathrm{C}$ ). These findings suggest the use of polysulfone PSU-modified alumina nanocomposites with enhanced mechanical and wear properties, without a sacrifice in transparency, for direct dental applications.

\section{Acknowledgements}

The authors would like to acknowledge funding from the Spanish Ministerio de Economía y Competitividad under grant MAT2014-57557-R. R. Prof. Ozisik would like to acknowledge financial support from the U.S. National Science Foundation (CMMI - 1538730). The authors also would like to thank I. García and A. Cervera from Euroortodoncia for their invaluable help in nanocomposite processing.

\section{References}

1 J. S. Rusell, J. Orthod, 2005, 32, 146-163.

2 B. Bazakidou, R. S. Nanda, J. M. G. Duncanson and P. Sinha, Am. J. Orthod. Dentofacial. Orthoped., 1997, 112, 138-144.
3 P. C. Aknin, R. S. Nanda, J. M. G. Duncanson, G. F. Currier and P. Sinha, Am. J. Orthod. Dentofacial. Orthoped., 1996, 109, 22-27.

4 P. V. Angolkar, S. Kapila, J. R. Duncanson and R. Nanda, Am. J. Orthod. Dentofacial. Orthoped., 1990, 98, 499-506.

5 S. Arici and D. Regan, Br. J. Orthod., 1997, 24, 133-137.

6 D. H. Pratten, K. Popli, N. Germane and J. C. Gunsolley, Am. J. Orthod. Dentofacial. Orthoped., 1990, 98, 398-403.

7 T. Eliades, Am. J. Orthod. Dentofacial. Orthoped., 2007, 131, 253-262.

8 M. D. Guiver, S. Croteau, J. D. Hazlett and O. Kutowy, Br. Polym. J., 1990, 23, 29-39.

9 M. S. Gaur, P. K. Singh, Suruchi and R. S. Chauhan, J. Therm. Anal. Calorim., 2013, 111, 743-751.

10 S. Anaya, B. Serrano and B. Herrero, ACS Appl Mater. Interfaces, 2014, 6, 14460-14468.

11 A. Dasari, Z. Z. Yu and Y. W. Mai, Mater. Sci. Eng., R, 2009, 63, 31-80.

12 W. G. Sawyer, K. D. Freudenberg, P. Bhimaraj and L. S. Schadler, Wear, 2003, 254, 573-580.

13 D. L. Burris, S. Zhao, R. Duncan, J. Lowitz, S. S. Perry, L. S. Schadler and W. G. Sawyer, Wear, 2009, 267, 653-660.

14 J. Bijwe, N. Aranganathan, S. Sharma, N. Dureja and R. Kumar, Wear, 2012, 296, 693-701.

15 S. Bahadur and C. Sunkara, Wear, 2005, 258, 1411-1421.

$16 \mathrm{~S}$. Bahadur and C. J. Schwartz, The influence of nanoparticle fillers in polymer matrices on the formation and stability of transfer film during wear, Blsevier Ltd, 2008, vol. 55.

17 S. R. Chauhan and S. Thakur, Mater. Des., 2013, 51, 398-408. 18 N. Moussaif, S. Irusta, C. Yagüe, M. Arruebo, J. G. Meier, C. Crespo, M. A. Jimenez and J. Santamaría, Polymer, 2010, 51, 6132-6139.

19 S. Kango, S. Kalia, A. Celli, J. Njuguna, Y. Habibi and

R. Kumar, Prog. Polym. Sci., 2013, 38, 1232-1261.

20 S. K. Kumar, N. Jouault, B. Benicewicz and T. Neely, Macromolecules, 2013, 46, 3199-3214.

21 J. Choi, C. M. Hui, M. Schmitt, J. Pietrasik, S. Margel, K. Matyjazsewski and M. R. Bockstaller, Langmuir, 2013, 29, 6452-6459.

22 P. Akcora, S. K. Kumar, V. García Sakai, Y. Li, B. C. Benicewicz and L. S. Schadler, Macromolecules, 2010, 43, 8275-8281.

23 C. Dizman, S. Ates, L. Torun and Y. Yagci, Beilstein J. Org. Chem., 2010, 6, 1-7.

24 G. Yilmaz, H. Toiserkani, D. O. Demirkol, S. Sakarya, S. Timur, Y. Yagci and L. Torun, J. Polym. Sci, Part A: Polym Chem., 2011, 49, 110-117.

25 S. Gupta, P. C. Ramamurthy and G. Madras, Ind. Eng. Chem. Res., 2011, 50, 6585-6593.

26 N. Tsubokawa, K. Maruyama, Y. Sone and M. Shimomura, Polym. J., 1989, 21, 475-481.

27 R. Huisgen, Angew. Chem., Int. Ed. Engl, 1963, 2, 565-598.

28 S. Bräse, C. Gil, K. Knepper and V. Zimmermann, Angew. Chem, Int. Ed., 2005, 44, 5188-5240.

29 P. Scheiner, Tetrahedron, 1967, 24, 349.

$30 \mathrm{G}$. Socrates, Infrared and Raman characteristic group frequencies, John Willey and Sons, Chichester, 3rd edn, 2001. 
31 J. Hopkins and J. P. S. Badyal, Langmuir, 1996, 12, 42054210.

32 V. Miguelina, C. Guillermo, T. Tatiana, O. M. Guadalupe, M. Juan, O. Roberto, A. Instituto, P. Nacional and C. Ticomán, XIII Congr. Técnico Científico ININ-SUTIN, 2000, pp. 81-85.

33 M. Bryjak, I. Gancarz, G. Poźniak and W. Tylus, Eur. Polym. J., $2002,38,717-726$.

34 M. Vásquez Ortega, in 98 XIII Congreso Técnico Científico ININ-SUTIN, 2004, p. 77.

35 M. Wahlander, F. Nilsson, E. Larsson, W. C. Tsai, H. Hillborg, A. Carlmark, U. W. Gedde and E. Malmstrom, Polymer, 2015, 55, 2125-2138.

36 T. Orhan, S. Ates, J. Hacaloglu and Y. Yagci, J. Anal. Appl. Pyrolysis, 2012, 94, 146-152.

37 D. Olmos, S. G. Prolongo and J. González-Benito, Composites, Part B, 2014, 61, 307-314.

38 G. Gedler, V. Antunes, V. Realinho and J. I. Velasco, Polym. Degrad. Stab., 2012, 97, 1297-1304.

39 Y.-Z. Wang, B. Yi, B. Wu, B. Yang and Y. Liu, J. Appl Polym. Sci., 2003, 89, 882-889.

40 L. Nayak, M. Rahaman, D. Khastgir and T. K. Chaki, Polym. Bull., 2011, 67, 1029-1044.

41 L. Nayak, D. Khastgir and T. K. Chaki,J. Mater. Sci., 2013, 48, 1492-1502.

42 R. Munter, Proc. Est. Acad. Sci., Chem., 2001, 50, 59-80. 43 A.-Y. Jee and M. Lee, Polym. Test., 2010, 29, 95-99.
44 S. L. Gao and B. Mäder, Composites, Part A, 2002, 33, 559576.

45 S. Zhao, L. S. Schadler, R. Duncan, H. Hillborg and T. Auletta, Compos Sci. Technol., 2008, 68, 2965-2975.

46 P. S. Uskokovic, C. Y. Tang, C. P. Tsui, N. Ignjatovic and D. P. Uskokovic, J. Eur. Ceram. Soc., 2007, 27, 1559-1564.

47 G. M. Odegard, T. S. Gates and H. M. Herring, Exp. Mech., $2005,45,130-136$.

48 B. N. Lucas, C. T. Rosenmayer and W. C. Oliver, Mater. Res Soc. Symp. Proc., 1998, 505, 97-102.

49 T. A. Witten, M. Rubinstein and R. H. Colby, J. Phys. II, 1993, 3, 367-383.

50 Y. Duan, P. Cong, X. Liu and T. Li, J. Macromol. Sci, Part B: Phys. , 2009, 48, 604-616.

51 M. Mandhakini, T. Lakshmikandhan, A. Chandramohan and M. Alagar, Tribol. Lett., 2014, 54, 67-79.

52 D. L. Burris and W. G. Sawyer, Wear, 2006, 260, 915-918.

53 C. J. Schwartz and S. Bahadur, Wear, 2000, 237, 261-273.

54 P. Bhimaraj, D. L. Burris, J. Action, W. G. Sawyer, C. G. Toney, R. W. Siegel and L. S. Schadler, Wear, 2005, 258, 1437-1443.

55 L.-H. Sun, Z.-G. Yang and X.-H. Li, Wear, 2008, 264, 693-700. 56 Q. Wang, Q. Xue, H. Liu, W. Shen and J. Xu, Wear, 1996, 198, 216-219.

57 G. Malucelli and F. Marino, Abrasion Resist. Mater., 2012,118.

58 G. Zhang, A. K. Schlarb, S. Tria and O. Elkedim, Compos. Sci. Technol, 2008, 68, 3073-3080. 